\title{
Knowledge Management and Performance of Organizations: A Case Study of Selected Food and Beverage Firms
}

Submitted 25/04/20, $1^{\text {st }}$ revision 28/05/20, $2^{\text {nd }}$ revision 09/06/20, accepted 20/07/20

\author{
Victoria O. Akpa ${ }^{1}$, Babatunde H. Akinlabi ${ }^{2}$, \\ Priscilla T. Asikhia ${ }^{3}$, Goodluck K. Nnorom ${ }^{4}$
}

\begin{abstract}
:
Purpose: The objective of this paper is to ascertain the effect of knowledge management on the performance of organizations in Nigerian food and beverage manufacturing sector. Design/Approach/Methodology: To achieve the stated objective, the study used survey research design, with 320 samples from a population of 1587 employees of selected food and beverage firms in Nigeria. A validated questionnaire was used to collect data and structural equation modelling was used to analyze the data.

Findings: Results showed that knowledge creation had a significant negative effect on innovation and knowledge sharing had a significant positive effect on innovation. The findings also revealed that knowledge creation has a significant positive effect on job satisfaction while knowledge sharing had an insignificant negative effect on job satisfaction.

Practical Implication: The results can be used in efforts to improve the performance of the manufacturing sector in Nigeria and other developing countries by adopting knowledge management initiatives to enhance performance levels.

Originality/Value: This study is an original study and it adds to scholarly debate on effect of knowledge management and the performance of manufacturing firms by giving evidence from a developing country. Manufacturing firms can adopt innovation as a channel for knowledge management to boost the performance of their businesses.
\end{abstract}

Keywords: Innovation, job satisfaction, knowledge creation, knowledge management, knowledge sharing, organizational performance.

JEL codes: M20, M31, M54.

Paper Type: Research Article.

ISSN: 2241-4754, H index 10, Q3.

\footnotetext{
${ }^{1}$ Department of Business Administration and Marketing, Babcock University, Ilishan-Remo Ogun State, Nigeria, ORCID: 0000-0002-6495-4343,e-mail: akpav@babcock.edu.ng

${ }^{2}$ Department of Business Administration and Marketing, Babcock University, Ilishan-

RemoOgun State, Nigeria, email: akinlabib@babcock.edu.ng

${ }^{3}$ Department of Business Administration and Marketing, Babcock University, Ilishan-Remo

Ogun State, Nigeria, email: priscillaasikhia@yahoo.com

${ }^{4}$ Department of Business Administration and Marketing, Babcock University, Ilishan-Remo

Ogun State, Nigeria, email: nnoromg@babcock.edu.ng
} 


\section{Introduction}

Globally, the manufacturing sector plays a significant role in the development and growth of every economy. Performance of business organizations worldwide has elicited concerns from professionals particularly in the manufacturing segment of most economies. However, these trepidations are debatable because of the progressively essential role the manufacturing sector in the economy globally. Knowledge has become a major source of wealth, and employees are the assets. An essential issue for both individual and organizations is how to manage this knowledge (Wang and Wu, 2016). According to Olja et al. (2017), organizations built on labor and capital are gradually being substituted by the ones built on knowledge capabilities since their accomplishment and survival is acclimatized by creating new, innovative, and better services and products.

Organizations own considerable extents of knowledge spread across uncountable organized and unorganized sources. The speed of acquiring knowledge is growing as technology enables the fast interchange of information. The capability to advance processes and deliver innovative goods and services to the market at cheaper and faster rates hinges on creating, sharing, applying, and converting knowledge (Abbas and Lagraa, 2017). Several organizations are working hard to be more efficient in knowledge management implementation (Yang and Chen, 2009). Knowledge management is emerging in business world as a strategic source that increases an organization's possibility of achieving competitive advantage (Andrej, 2017). It is also an important tool that directs the economy to a positive stage and advances the relationship concerning manufacturing organizations and the world at large (Faluyi, 2018; Kambey et al., 2018).

Generally, to sustain growth, innovation and competitive edge, organizations are required to manage knowledge well. Nevertheless, knowledge management in food and beverage manufacturing firms in Nigeria has turned out to be a multifaceted and thought-provoking task in recent times (Faluyi, 2018). As pressure rises for growth, innovation through effective knowledge management conveys hope for the solution. Knowledge management certainly facilitates innovation, which in turn leads to organizational performance (Abbas and Lagraa, 2017). Many organizations focus on continuous performance because it is the only way they can grow and develop. Yang and Chen (2009) submit that an organization needs to engender an environment that integrates organization performance with knowledge management to enable creation, sharing, application and knowledge conversion if they are to succeed.

Many food and beverage manufacturing firms in Nigeria are facing high failure rate caused by huge funds wastage, unproductive management plan and financial crunches (Nwonyuku, 2016). These may possibly be accredited to poor knowledge management strategies among workers and the firm. As a result, it is difficult for several of these companies to keep up to the volume of contribution that will retain them in business. With these existing problems, knowledge management is essential 
in recent threshold of organizations if they are to flourish in their performance (Chawla and Joshi, 2017). Thus, this work explores the effect of knowledge management on the performance of selected food and beverage industries in Lagos State, Nigeria.

Inability to properly create, share, apply and convert knowledge strategies between the employees and customers to give the organization a preferred image, has been a problem in food and beverage industries. According to Adebisi and Abatunde (2012), food and beverage industries in Nigeria are faced with the challenge of customer shortage because of unsatisfactory management of knowledge within the organization. Inability to create knowledge according to Didii (2017) is one of the utmost problems faced by the Nigerian economy. The problem turned out to be more noticeable by globalization and all that go along with it. The manufacturing sector in Nigeria is at the brink of collapse and many employees may be thrown out of jobs. Nigeria has also turned into a discarding ground for all categories of foreign products (Anwarul et al., 2017). Some products and services of the manufacturing sector in Nigerian, according to Anwarul et al. (2017), cannot contest favorably globally with goods from advanced countries most especially Europe and America. The pursuit of developing new innovations is not given serious attention in Nigeria among food and beverage manufacturing companies (Adebisi and Babatunde, 2012). Hence, there is need for strategic innovation through knowledge creation capability, which is a crucial factor for industrial development. Based on the above problems, the effect of knowledge creation on innovation among food and beverage firms in Nigeria is being investigated.

According to Siemens (2007) common internal barriers to knowledge sharing include inadequate communication among different units in the organization and the propensity of some workers to hoard knowledge. This may affect the efficiency and effectiveness of employees in the organizations. Job satisfaction among employees is significant for organizations but will be difficult to attain if there is a lack of knowledge sharing. This and many more barriers relating to knowledge sharing has caused low satisfaction among worker and dawdling inflow and outflow of information among employees (Teh and Sun, 2012; Aliev and Sigov, 2017).

\section{Literature Review}

This segment addresses the definitions and explanation of knowledge management concept (knowledge creation and sharing) and organizational performance (innovation and job satisfaction).

\subsection{Knowledge Management}

The management of knowledge is a necessity in every firm. Knowledge management $(\mathrm{KM})$ has to do with an organizations' ability to retain and share resources of knowledge for sustainable competitive edge (Chuang, 2004). It has to 
do with capturing, and developing dissemination, and effectively using organizational knowledge (Davenport and Prusak, 1998). KM describes the processes and strategies of identifying, obtaining, converting, applying, sharing, and guarding knowledge to improve the competitiveness of an organization. Generally, KM practices are considered a process that has to do with the management of knowledge in order to meet modern and evolving requirements, recognizing and taking advantage of current knowledge resources and developing new opportunities (Hsiu-Fen, 2007). It is the organized management of an organizations' knowledge resources which entails the initiative procedure, plans and systems that maintain and improve the creation, sharing, valuation, and storage retrieving and converting knowledge and information properties into knowledge that is readily accessible with the intention of enhancing organizational performance (Alan, 2012).

Knowledge management is an intentional action in an organization and includes key knowledge identification, new knowledge generation, and the transference of knowledge amid and among workers (Gomezelj et al., 2011). When the management of knowledge is properly done, the performance of the organization improves. The organization also gains competitive advantage because it makes its workers becomes sharper and smarter enough to process and break down jobs (Alryarat and Alhawari, 2008; Cieslik and Michalek, 2018).

\subsubsection{Knowledge Creation}

Knowledge creation has to do with innovating, developing, inventing information and knowledge into that which is already existing to improve organizational performance. Ting (2017) described knowledge creation as developing newfangled knowledge or information or changing current content. According to Chen et al. (2015), knowledge creation consists of new application of knowledge or substituting the present content contained in the tacit and explicit knowledge of the organization. Firms are obliged to look for fresh information and knowledge, outside and within the organizations. Knowledge creation could also be generating fresh and different ideas, the acknowledging earlier unnoticed patterns, synthesizing distinct disciplines, and developing new-fangled processes (Bhatt, 2001; Davenport and Prusak, 1998).

Large and small organizations can create and acquire fresh knowledge through outsourcing or benchmarking replication (Abou-Zeid, 2002). This procedure creates fresh knowledge inside firm and can be transformed to fundamental achievement issue and incessant innovation (Bhatt, 2001; Gold and Malhotra, 2001). New generation of leaders according to Chirico (2008), need to generate fresh knowledge, which will help the competitiveness and performance of the organization throughout the transfer of ownership and leadership rights. As a result, knowledge creation process is of utmost importance to the succession process of every organization. Periodic review is highly necessary to preserve the knowledge and skills taught because human memory is deficient irrespective of the age or background of the learner. 


\subsubsection{Knowledge Sharing}

Bartol and Srivastava (2002) assert that knowledge sharing has to do with sharing of pertinent facts, thoughts, proposals, and know-how with one another in an organization. It is a procedure where workers communally interchange their implicit (tacit) and unambiguous information to generate new-fangled knowledge (Sirje, 2012; Hooff and Ridder, 2004). King (2007) defined knowledge sharing as persons' knowledge, intuitions and experiences at work that are associated with the present tasks that individual does at work. Hooff and Ridder (2004) add that knowledge sharing entails 'donating' (telling others what your personal intellectual capital is) and 'collecting' (asking coworkers to share their intellectual capital with you) aspects of sharing.

Knowledge sharing is a kind of communal dealing amid individuals because authentic knowledge-sharing is not people-based but individual-based (Riege, 2005). The main intention of effective knowledge-sharing according to Ling (2015) centers on organizations utmost critical needs. The needs include guaranteeing that the system is in agreement with strategy, making sure that organization build trust by emphasizing on essential qualities rather than values, adopting excellent practices, resolving customer's difficulties promptly, permitting subordinates to resolve the difficulties they come across without meddling by the top management, and introducing customer feedback as part of the process in the new product development (Ling, 2015).

\subsection{Organizational Performance}

The idea of organizational performance is central to organizations since the main purpose of firms is to make profit (Olanipekun et al., 2015). Daft (2010) described the performance of an organization as the capacity to reach its goals by efficiently and effectively using their resources. Organizational performance describes how efficient a firm has been in its mission to attain specified goals, which includes how well its resources are deployed, how well goals fixed are achieved, how effective is the Board (Pierre et al., 2009; Suryanto et al., 2017).

Jenatabadi (2015) sees performance as how far an organization achieves its goals devoid of being constrained to debilitate its means or place extreme pressure on the workers. It is also the assessment of the elements that evaluate the competence and aptitude of an organization to attain the constituents' aspiration heights through effectiveness, efficiency, or social significance standards. Syafarudin (2016) adds that it is the result of real consequence shaped by an organization which is evaluated and compared with the anticipated results.

Organizational performance is contingent on the capacity of an organization to generate value for its clienteles (Porter, 1986). A performing organization according to Radu and Taicu (2009), is one in which managers create value for its owners which is achieved when the earnings on capital put in are greater than the costs. 
Lusthaus et al. (2002) add that the performance of organizations is generally signified by customer and employee satisfaction, sustainability of its economy, social/environmental obligation, and its public image. Innovation and job satisfaction of employees are integral parts of organizational performance for this paper.

\subsubsection{Innovation}

Innovation has to do with introducing and making new types of products or services that are different from previous design by paying more attention to the quality of the new product which complements the short comings of previous outcomes (Atalay et al., 2013). Innovation can involve the new product or service, procedure, skill, branching out into a new market, or using new material. It can also be an acceptance of a novel knowledge or idea (Zia, 2017). Innovation can generate maintainable growth which could lead to competitive advantage in both external and internal markets. It allows organizations to present new and/or enhanced products to the market earlier than their opponents. Organizations try to be inventive and creative to generate effective and efficient performance (Polder et al., 2009; Goraczkowska, 2018).

Innovation types include but not limited to process, product or service, marketing, and organizational innovation (OECD, 2005). Two types of organizational innovation most mentioned are the product or service and process. Introducing new products or substantially upgraded with respect to its characteristics or anticipated use is called product innovation. It is the modifications or novelty introduced in the product or service. Creating new services or product as well as novel ways of distributing or supplying the goods to the clients is called process innovation. It also refers to the newness and originality introduced in the technique or procedure of creating products or services (Damanpour and Evan, 1984; Blumentritt, 2004). Product innovations are usually client-focused and market-oriented while process innovations focus on the interior and are presented for efficiency advantages. Product innovation advances an organization's external product mix while process innovation increases a firm's interior operations mix (Laforet and Tann, 2006).

\subsubsection{Job Satisfaction}

Job satisfaction is an essential characteristic which is often measured by organizations. It is mostly acknowledged as a multidimensional concept that consist of how workers feel about a multiplicity of extrinsic and intrinsic job components (Robbins and Judge, 2013). It is also the longing and contentment that comes from evaluating your work and experience at work (Rizwan et al., 2013). It is also an optimistic emotion ensuing from experiences at workplace (Akafo and Boateng, 2015).

Job satisfaction is essential in the performance of workers in organizations. Workers are predominantly satisfied with the work development of their life in terms of security and accomplishment which could lead to increased obligation, loyalty, and 
reduced absenteeism employee turnover (Abenyo et al., 2018). Job satisfaction of workers has been observed as a major factor that leads to upsurge in employee effectiveness, efficiency, commitment, and organizational performance. When workers are content with their jobs, they tend to be moved to carry out their tasks enthusiastically which escalates organizational performance in the long could run (Judge et al., 2017).

Two hypotheses are generated as basic assumptions between the variables of the study based on the literature review above as follows:

H1: Knowledge creation and sharing do not significantly influence innovation of selected food and beverage firms in Lagos state, Nigeria.

H2: Knowledge creation and sharing have no significant effect on employee satisfaction of selected food and beverage firms in Lagos state, Nigeria.

\subsection{Theoretical Framework}

Knowledge-based view (KBV) theory was proposed by Grant (2002). This theory states that organizations exist to create, convert, and transfer knowledge for competitive edge (Kogut and Zander, 1992). In addition, knowledge is an elusive varied and hard to copy means which has diverse types at diverse echelons of the firm and connected with the outcomes of performance for competitive edge. The knowledge-based view of an organization talks about the concerns of the being, the limits, and the multi-person's firm internal organization. The key expounding factor is knowledge. Its nature is a vital determining factor that improves the understanding the organization and performance of firms (Foss, 2003).

The knowledge-based view recognizes knowledge as the utmost important resource of an organization where every other resource hang on (Kraaijenbrink et al., 2010). Knowledge-based view explains how organizations generate, obtain, process, use, guard, and transmit knowledge inside the organization and its capacity to build competitive edge for the organization and its stability. The theory is pertinent to this work since the knowledge-based view theory recognizes knowledge as the utmost advantageously key resource of any organization (Barney, 1996). Organizations are therefore obligated to distinguish the knowledge they process to comprehend what creates greater performance. An organization may have exclusive and treasured knowledge but may not be able to generate and withstand a competitive edge to improve performance unless it uses what it has effectively.

\section{Methodology}

The work used of cross-sectional survey research design and utilized descriptive and multivariate analysis methods. Similar study, for example Kising'u (2017), Mark, Philip, and Adrian (2009) adopted this method. The population consists of 1587 top and middle level staff of selected food and beverage firms (Nestle Nigeria Plc, 
Unilever Nigeria Plc and Honeywell Flour Mill). Yamane (1967) formula was used to select 320 samples from the population of the study. To arrive at a well representative sample for the study, stratified sampling method was employed. Data was gathered through a self-developed structured questionnaire. Thus, a six-point Likert type scale was employed in the study. The instrument was validated with validity levels $>0.5$ and reliability values $>0.7$. The data were analyzed using Structural Equation Model through analysis of moment structure (AMOS, v.20) for data analysis where variables are as follows:

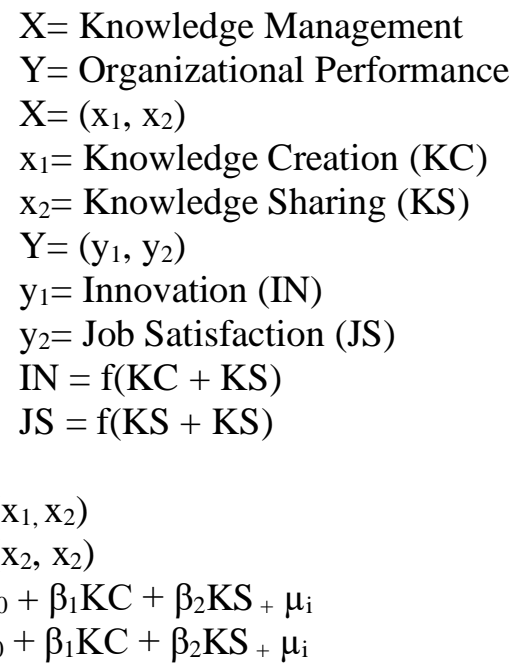

$\mathrm{IN}=\alpha_{0}+\beta_{1} \mathrm{KC}+\beta_{2} \mathrm{KS}+\mu_{\mathrm{i}}$

$\mathrm{JS}=\alpha_{0}+\beta_{1} \mathrm{KC}+\beta_{2} \mathrm{KS}+\mu_{\mathrm{i}}$

\section{Findings and Discussions}

\subsection{Hypothesis Test H1}

H1: Knowledge creation and sharing do not significantly influence innovation of selected food and beverage firms in Lagos state, Nigeria.

Figure 1. Path Diagram of Knowledge Creation, Sharing and Innovation

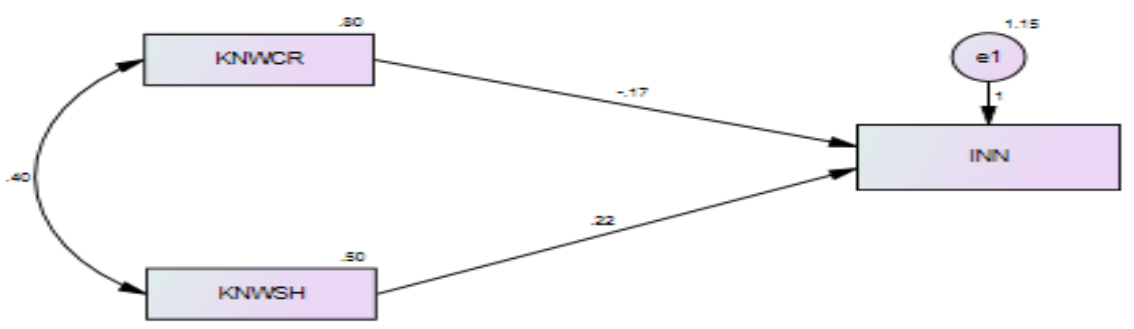

Source: Amos Graphics (2020). 
Amos graphics tool was used to run a structural equation to test the effect of knowledge creation and sharing on innovation. From Figure 1, knowledge creation has a negative effect on innovation with a regression coefficient value -0.17 . This indicates that as knowledge creation activities increase by 1 unit, innovation decreases by -1.7 . In other words, the result implies that when knowledge creation (KNWCR) goes up by 1 , innovation (INN) goes down by 0.17 .

Figure 1 further reveals that, knowledge sharing has positive effect on innovation with a regression value of 0.22 approximately. This indicates that as knowledge sharing activities increase by 1unit, innovation increases by 0.22 . When knowledge sharing (KNWSH) goes up by 1 unit, innovation (INN) goes up by 0.22 .

Table 1. Regression Weights for HI

\begin{tabular}{|ll|rrrrr|}
\hline & & Estimate & S.E. & Z & P & Label \\
\hline INN <--- & KNWSH & .224 & .105 & 2.129 & .033 & par_1 \\
INN <--- & KNWCR & -.172 & .083 & -2.079 & .038 & par_2 \\
\hline
\end{tabular}

Source: Amos Output (2020).

Table 1 shows the regression weights. The regression weight estimate for innovation and knowledge sharing is .224, and the standard error is .105. When the regression weight estimate is divided by the estimate of its standard error, it gives $z$ $=.224 / .105=2.129$, meaning that the regression weight estimate is 2.129 standard errors above zero. The probability of getting a critical ratio as large as 2.129 in absolute value is .033. This means that the regression weight for KNWSH in the prediction of INN is significantly different from zero at $0.05 \%$ level.

The regression weight estimate, for innovation and knowledge creation is -.172 , and the standard error is .083 with $z=-.172 / .083=-2.079$, meaning that the regression weight estimate is 2.079 standard errors below zero. The probability of getting a critical ratio as large as 2.079 in absolute value is .038 This means that the regression weight for KNWCR in the prediction of INN is significantly different from zero at $0.05 \%$ level. Thus, based on the results obtained, it is seen that knowledge creation has a significant negative effect on innovation while knowledge sharing has significant positive effect on innovation.

These variables and their linkages have been studied by different researchers (Bidmeshgipour et al., 2012; Kör and Maden, 2013). Knowledge creation was found to be very instrumental to the enhance innovation by acquiring, converting, and applying of newfangled and well nurtured ideas and connecting the knowledge power of organizations for innovative and superior services or products. Sylva et al. (2016) did a study on the impact of knowledge creation on innovation of manufacturing organizations in Nigeria. However, it was revealed that knowledge acquisition has the most impact on innovation. Eugenie and John (2017) studied 
knowledge creation and innovation performance. The findings of Sylva et al. (2016) and Eugenie and John (2017) are alike but differ in terms of methodology and research settings.

Ndegwa et al. (2015) investigated the effect of knowledge sharing on job satisfaction in top 10 enterprise and discovered that knowledge sharing had a positive and significant effect on job satisfaction. Lee and Wong (2015) studied knowledge sharing measurement in micro, small and medium-sized enterprises. The results show that firm size and knowledge sharing affected some facets of knowledge management performance in SMEs. Chawla and Joshi (2017) worked on the effect of knowledge sharing on performance of organizations in India. The results revealed that organizations awarded for business excellence have a positive relationship between knowledge sharing and organizational performance. The findings of Lee and Wong (2015) and Chawla and Joshi (2017) are similar, the findings show that knowledge sharing have a positive and significant relationship with organizational and learning performance. However, the studies differed clearly on methodology adopted and the contextual areas. Ngah and Razak (2010) investigated the effect of knowledge sharing practices on the performance of SMEs in Malaysia. They discovered that knowledge sharing has positive influence on the performance of organization.

\subsection{Hypothesis Test $\mathrm{H} 2$}

H2: Knowledge creation and sharing do not significantly affect job satisfaction of employees in selected food and beverage firms in Lagos state, Nigeria.

Figure 2. Path Diagram of Knowledge creation, sharing and job satisfaction

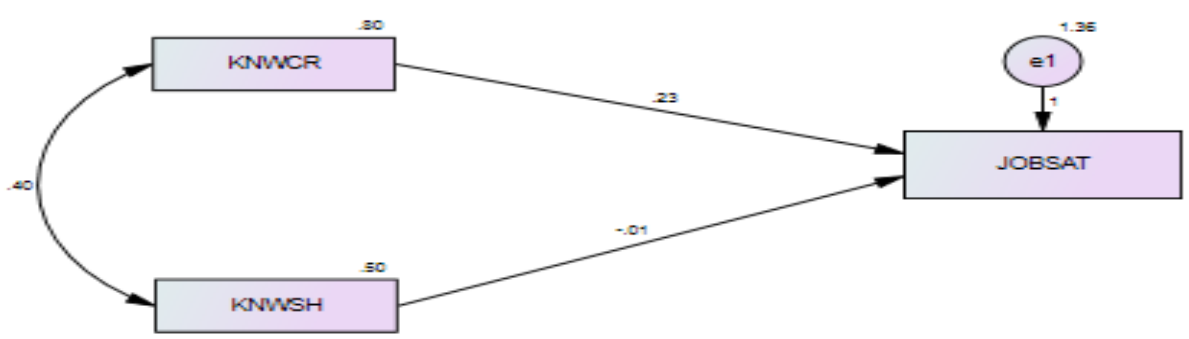

Source: Amos Graphics (2020).

Amos graphics tool was used to run a structural equation to test the effect of knowledge creation and sharing on innovation. From Figure 2, knowledge creation has a positive effect on job satisfaction with the regression coefficient value of 0.23. This indicates that as knowledge creation activities increase by lunit, job satisfaction increases by 0.23 . In other words, it implies that when knowledge creation (KNWCR) goes up by 1unit, job satisfaction (JOBSAT) goes up by 0.23 . 
Figure 2 reveals further that knowledge sharing has a negative impact on job satisfaction with a regression coefficient value of -0.01 . This shows that as knowledge sharing activities increase by 1 unit, job satisfaction decreases by 0.1 . When knowledge sharing (KNWSH) goes up by 1unit, job satisfaction (JOBSAT) goes down by 0.01 .

Table 2. Regression Weights for H2

\begin{tabular}{|ll|rrrrr|}
\hline & & Estimate & S.E. & Z & P & Label \\
\hline JOBSAT <--- & KNWCR & .232 & .090 & 2.580 & .010 & par_2 \\
JOBSAT <--- & KNWSH & -.014 & .114 & -.123 & .902 & par_3 \\
\hline
\end{tabular}

Source: Amos Output (2020).

Table 2 above shows the regression weight estimate being .232, and the standard error is .090 with $z=.232 / .090=2.580$, meaning that the regression weight estimate is 2.58 standard errors above zero. The probability of getting a critical ratio as large as 2.58 in absolute value is .010. This means that the regression weight for KNWCR in the prediction of JOBSAT is significantly different from zero at $0.05 \%$ level.

The regression weight estimate, for the linkage between knowledge sharing and job satisfaction is -.014 , with standard error .114 and $z=-.014 / .114=-.123$. This means that the regression weight estimate is 0.123 standard errors below zero. The probability of getting a critical ratio as large as 0.123 in absolute value is .902 . According to the analysis, the regression weight for KNWSH in the prediction of JOBSAT is not significantly different from zero at $0.05 \%$ level. Thus, based on the results obtained, it is seen that knowledge creation has a significant positive effect on job satisfaction while knowledge sharing has an insignificant negative effect on job satisfaction.

Valdez-Juárez et al. (2016) studied knowledge sharing, innovation, and SMEs performance. The findings revealed that knowledge sharing had significant effect on innovation and an insignificant effect on the level of SMEs' performance. Ndegwa et al. (2015) studied knowledge sharing, organizational learning, and top medium-sized companies' performance in Kenya. The study established that Knowledge sharing has significant influence on wealth creation, competitive edge, and social welfare. Bierly and Daly (2007) conducted a survey research examining the relationship between knowledge sharing strategies and firm performance, using a sample of top medium-sized manufacturing firms in USA. Using regression model, the results indicated that knowledge-sharing strategies significantly improve firm performance.

\section{Conclusion}

This study examined the effect of knowledge management on organizational performance of selected food and beverage firms in Lagos State Nigeria. Based on 
the findings and the discussions above, the study concludes that knowledge management is a veritable tool in improving innovation and job satisfaction level in the organization. Firms in Nigeria particularly in the Nigerian food and beverage sector are encouraged to adopt modern techniques in the creation and distribution of knowledge as this will contribution to the enhancement of innovation and job satisfaction in the organization.

\section{Limitations and Future Research Directions}

This work is on the effect of knowledge management (knowledge creation and sharing) on organizational performance (innovation and job satisfaction) of selected food and beverage firms in Lagos State Nigeria. There are other factors that have the capacity to influence organizational performance, such as strategic planning, management by objectives and so on. In the same vein, there are other possible influences of knowledge management such as enhancing organizational flexibility, competitive advantage and so on. Therefore, the researchers encourage that future research enquiries can focus on other variables or contexts that relate to the present study.

The use of cross-sectional survey design has its limitations by allowing the researcher to collect data from respondents at a point in time. Therefore, further research endeavors should look at other research designs such as longitudinal survey design that will allows the collection of data over a long period of time, thereby improving the robustness and veracity of research results. Moderators and other control variables can also be introduced to improve the results of the study.

\section{References:}

Abbas, S. Lagraa, J. 2017. Organizational performance in manufacturing companies a comparative study. Journal of Human Resource Management, 3(5), 22-34.

Abenyo, W., Darko, P.A., Frempong, L.N. 2018. The impact of job satisfaction on employees' loyalty and commitment: A comparative study among some selected sector in Ghana. European Journal of Business and Management, 10(12), 95-105.

Abou-Zeid, D. 2002. Information and information sources in tasks of varying complexity. Journal of the American Society for Information Science and Technology 53(7), 581-591.

Adebisi. J., Babatunde, O. 2012. Impact of knowledge management on organizational performance. Journal of Information Management, 6(3), 145-157.

Akafo, V., Boateng, P.A. 2015. Impact of reward and recognition on job satisfaction and motivation. European Journal of Business and Management, 7(4), 1-7.

Alan, F. 2012. Knowledge-management-definition. Retrieved from: http://www.KnowledgeManagementtools,Net/Knowledge-Management-Definition.html.

Aliev, I.M., Sigov, V.I. 2017. Creating a learning organization as an increase in the adaptability of a company's human capital to the volatility of the external environment. European Research Studies Journal, 20(4), 57-69. 
Alryarat, H., Alhawari, S. 2008. Towards customer knowledge relationship management: Integrating knowledge management and customer relationship. Journal of Information Management, 7(3), 145-157.

Andrej, N. 2017. Knowledge management and competitive advantage. Journal of business management, 50(1), 100-111.

Anwarul, M., Kumar, I., Ikeda, M. 2017. Effect of knowledge management on service innovation in academic libraries. International Federation of Library Associations and Institutions, 43(3), 266-280.

Atalay, M., Anafarta, N., Sarvan, F. 2013. The relationship between innovation and firm performance: Empirical evidence from Turkish automotive suppliers' industry. Procedia- Social and Behavioural Sciences, 75(1), 226-235.

Barney, J.B. 1996. The resource-based theory of the firm. Organization Science, 7(5), 469469.

Bartol, K., Srivastava, A. 2002. Encouraging knowledge sharing: The role of organizational reward systems. Journal of Leadership \& Organizational Studies, 9(1), 64-76.

Bhatt, G. 2001. Knowledge management in organizations: Examining the interaction between technologies, techniques, and people. Journal of Knowledge Management, $5(1), 68-75$.

Bidmeshgipour, M., Ismail, W.K.W., Omar, R. 2012. Knowledge management and organizational innovativeness in Iranian banking industry. Knowledge Management and E-Learning, 4(4), 481-499.

Bierly, P.E., Daly, P.S. 2007. Alternative knowledge strategies, competitive environment, and organizational performance in small manufacturing firms. Entrepreneurship Theory and Practice, 31(4), 493-516.

Blumentritt, T. 2004. Does small and mature has to mean dull? Defying the ho-hum at SMEs. Journal of Business Strategy, 25(1), 27-33.

Chawla, D., Joshi, H. 2017. A comparative study of knowledge management assessment in business excellence awarded and non-awarded organizations in India. SAGE, Global Business Review, 12(2), 279-295.

Chen, I., Chen, J., Edgington, F. 2015. Critical quality indicators of higher education. Total Quality Management \& Business Excellence, 3(4), 1-17.

Chirico, F. 2008. Knowledge accumulation in family firms: evidence from four case. International Small Business Journal, 26(4), 433-462.

Chuang, Y. 2004. Knowledge management and organizational performance. Journal of Knowledge Management, 14(6), 811-827.

Cieślik, A., Michałek, J.J. 2018. Process and product innovations, multi-product status and export performance: firm-level evidence from V-4 countries. Equilibrium. Quarterly Journal of Economics and Economic Policy, 13(2), 233-250. doi: 10.24136/eq.2018.012.

Daft, R.L. 2010. New era of management ( $9^{\text {th }}$ ed.). Australia: South-Western, Cengage Learning.

Damanpour, F., Evan, W. 1984. Organizational innovation and performance: The problem of organizational lag. Administrative Quarterly, 29(4), 392-409.

Davenport, T., Prusak, L. 1998. Working Knowledge. Boston, Harvard Business School.

Didii, S. 2017. Human resource management in the enhancement processes of knowledge management. Binus Business Review, 8(3), 167-173.

Eugenie, B., John, C.M. 2017. Knowledge management and business performance: Does innovation matter? Cogent Business \& Management, 4(1), 1-8. 
Faluyi, A. 2018. Knowledge management and organizational performance. International Journal of Knowledge Management, 5(1), 71-84.

Foss, N.J., Knudsen, T. 2003. The resource-based tangle: Towards a sustainable explanation of competitive advantage. Managerial and Decision Economics, 24(4), 291-307.

Gold, A., Malhotra, A., Segars, A. 2001. Knowledge management: An Organizational Capabilities Perspective. Journal of Management Information Systems, 18(1), 343.

Gomezelj, D., Biloslavo, R., Trnavcevic, A. 2011. Knowledge management and organizational culture in higher education institutions. Journal for East European Management Studies, 16(2), 111-139.

Gorączkowska, J. 2018. Influence of business support organizations on innovation activity in manufacturing companies in the Masovian Voivodeship in Poland. Equilibrium. Quarterly Journal of Economics and Economic Policy, 13(4), 741-759. doi: 10.24136/eq.2018.036.

Grant, R.M. 2002. The resource-based theory of competitive advantage: Implications for strategy formulation. California Management Review, 33(3), 114-135.

Hooff, H., Ridder, K. 2004. Knowing in practice: enacting a collective capability in distributed organizing. Organization Science, 13(3), 249-273.

Hsiu-Fen, L. 2007. A stage model of knowledge management: an empirical investigation of process and effectiveness. Journal of Information Science, 33(6), 643-659.

Jenatabadi, H.S. 2015. An overview of organizational performance index: Definitions and measurement. Department of Science and Technology Studies University of Malaya, Kuala Lumpur, Malaysia.

Judge, W., Kammeyer-Mueller, H. 2017. Job attitudes, job satisfaction, and a change job affect: A century of continuity and of a change. Journal of Applied Psychology, 54 (1), 101-114.

Kambey, J.P., Wuryaningrat, N.F., Kumajas, L.I. 2018. Examining leadership and knowledge sharing role on small and medium enterprises innovation capabilities. International Journal of Economics and Business Administration, 6(1), 24-38.

King, J. 2007. The reification of absorptive capacity: A critical review and rejuvenation of the construct. Academy of Management Review, 31(4), 833-863.

Kising'u, T. 2017. Role of strategic leadership for sustainable competitive advantage in Kenyan public and private universities. (Unpublished PhD thesis), Jomo Kenyatta University of Agriculture and Technology, Kenya.

Kogut, F., Zandeer, G. 1992. Knowledge of the firm, combinative capabilities, and the replication of technology. Organization Science, 3(3), 383-399.

Kör, B., Maden, C. 2013. The Relationship between Knowledge Management and Innovation in Turkish Service and High-Tech Firms. International Journal of Business and Social Science, 4(4), 293-304.

Kraaijenbrink, J., Spender, J., Groen, A. 2010. The resource-based view: a review and assessment of its critiques. Journal of Management, 36(1), 349-372.

Laforet, S., Tann, J. 2006. Innovative characteristics of small manufacturing firms. Journal of Small Business and Enterprise Development, 13(3), 363-380.

Lee, C., Wong, K. 2015. Knowledge management performance measurement in micro-, small-and medium-sized enterprises: An exploratory study. SAGE Business Information Review, 32(4), 204-211.

Ling, H. 2015. Knowledge management and competitive advantage. Journal of Management, 36(1), 18-30. 
Lusthaus, C., Adrien, M., Anderson, G., Carden, F., Montalvan, G. 2002. Organizational assessment: A framework for improving performance. International Development Research Center/Inter-American Development Bank.

Mark, S., Philip, L., Adrian, T. 2009. Research methods for business students ( $5^{\text {th }}$ ed.). Edimburgh Gate, Prentice Hall.

Ndegwa, J., Machuki, V., Maalu, J., Awino, Z., Iraki, X. 2015. Knowledge sharing, organizational learning, and performance of top 100 medium enterprises in Kenya. Paper presented at 1 DBA-Africa management review international conference. http://journals.uonbi.ac.ke/damr/article/viewFile/1292/1091

Ngah, R., Razak, A.I. 2010. The Effect of Knowledge Sharing on Organizational Performance in Small and Medium Enterprises. Journal of Knowledge Management Practice, 3(3), 82-91.

Nwonyuku, A. 2016. Knowledge management in food and beverage sector in Nigeria Knowledge, and Management, 1(24), 209-222.

OECD. 2005. Oslo's manual. Paris, France, OECD.

Olanipekun, W.D., Abioro, M.A., Akanni, L.F., Arulogun, O.O., Rabiu, R.O. 2015. Impact of strategic management on competitive advantage and organizational performance evidence from Nigerian bottling company. Journal of Policy and Development Studies, 9(2), 185-198.

Olja, A., Dragan, T., Iztok, P., Polona, S. 2017. Strategic aspect of knowledge management. Journal of Management, 50(2), 163-177.

Pierre, R., Devinney, Yip, G., Gerry, J. 2009. Measuring organizational performance: Towards methodological best practice. Journal of Management, 35(3), 718-804.

Polder, M., Leeuwen, G.V., Mohnen, P., Wladimir, P. 2009. Productivity effect of innovation modes. Statistics of Netherlands, Discussion Paper, 09033.

Porter, M.E. 1986. Changing patterns of international competition. California Management Review, 28(3), 40-52.

Radu, F., Taicu, M. 2009. Considerations regarding the concepts and indications of the economic-financial performance. Theoretical and Applied Economics, 5(534), 124133.

Riege, D. 2005. Using knowledge sharing performance measurement systems for organizations: Does it work in dynamic environments? Management Accounting Research, 23(4), 296-311.

Rizwan, M., Ajmal, Z., Gill, A.S., Hameed, N., Iqbal, S., Waqas, A. 2013. Collision of work with life and its impact on job satisfaction. Journal of Basic and Applied Scientific Research, 3(12), 175-184.

Robbins, S.P., Judge, T.A. 2013. Organizational behavior (15 ${ }^{\text {th }}$ ed.). Boston, Pearson.

Siemens, A. 2007. Significance of knowledge sharing and organizational performance. Journal of knowledge management, 14(5), 499-512.

Sirje, D. 2012. Using mentoring and storytelling to transfer knowledge in the workplace. Journal of Management Information Systems, 18(1), 95-114.

Suryanto, T., Thalassinos, E.J., Thalassinos, I.E. 2017. Board Characteristics, Audit Committee and Audit Quality: The Case of Indonesia. International Journal of Economics and Business Administration, 5(3), 44-57, DOI: 10.35808/ijeba/134.

Syafarudin, D. 2016. Impact of leadership on organizational performance. A case study of D\&R cambric communication. (Unpublished Doctoral Dissertation), University of Applied Sciences. 
Sylva, W., Ofoegbu, C.W., Akpan, E.E. 2016. The Impact of Knowledge Management on Product Innovation of Manufacturing Firms in Nigeria. Information and Knowledge Management, 6(6), 78-87.

Teh, A., Suh, E. 2012. The influence of knowledge sharing on innovation performance. SAGE Journal of Information Science, 35(6), 635-659.

Ting, A. 2017. Importance versus practice of knowledge creation in manufacturing companies. SAGE Business Information Review, 33(4), 232-240.

Valdez-Juárez, L.E., García-Pérez de Lema, D., Maldonado-Guzmán, G. 2016. Management of knowledge, innovation, and performance in SMEs. Interdisciplinary Journal of Information, Knowledge, and Management, 11(4), 141-176.

Wang A., Wu, S. 2016. The role of Knowledge management and innovation performance. SAGE Journal of Information Science, 32(6), 222-242.

Yamane, T. 1967. Statistics: An Introductory Analysis (2nd Ed.). New York, Harper \& Row.

Yang, E., Chen, U. 2009. Knowledge management and organizational performance. Journal of Business Research, 1(3), 252-264.

Zia, S. 2017. Innovation and knowledge management: a literature review and research frameworks. Journal of Quality and Technology Management, 13(1), 99-116. 